\title{
A BRIEF REVIEW OF CHRONIC EXERCISE INTERVENTION TO PREVENT AUTONOMIC NERVOUS SYSTEM CHANGES DURING THE AGING PROCESS
}

\author{
Rogério Brandão Wichi, ${ }^{\mathrm{I}}$ Kátia De Angelis, ${ }^{\mathrm{I}}$ Lia Jones, ${ }^{\text {II }}$ Maria Claudia Irigoyen ${ }^{\mathrm{III}}$
}

doi: 10.1590/S1807-59322009000300017

\begin{abstract}
Wichi RB, De Angelis K, Jones L, Irigoyen MC. A brief review of chronic exercise intervention to prevent autonomic nervous system changes during the aging process. Clinics. 2009;64(3):253-8.

The aging process is associated with alterations in the cardiovascular and autonomic nervous systems. Autonomic changes related to aging involve parasympathetic and sympathetic alterations leading to a higher incidence of cardiovascular disease morbidity and mortality. Several studies have suggested that physical exercise is effective in preventing deleterious changes. Chronic exercise in geriatrics seems to be associated with improvement in the cardiovascular system and seems to promote a healthy lifestyle. In this review, we address the major effects of aging on the autonomic nervous system in the context of cardiovascular control. We examine the use of chronic exercise to prevent cardiovascular changes during the aging process.
\end{abstract}

KEYWORDS: Aging; Cardiovascular System; Autonomic Nervous System; Physical Exercise.

\section{INTRODUCTION}

The rates of cardiovascular disease morbidity and mortality increase steeply with advancing age. ${ }^{1}$ Aging is a physiological process related to morphological and functional changes in the cardiovascular and autonomic nervous systems. This process is related to higher incidence rates of cardiovascular disease, including hypertension, heart failure and myocardial infarction. ${ }^{2}$ Therefore, the literature suggests that aging is a risk factor for cardiovascular disease. In addition, environmental factors and sedentary lifestyle can also be related to cardiovascular disease. ${ }^{3}$ Changes in the autonomic nervous system are partly responsible for cardiovascular complications associated with aging and a sedentary lifestyle. In this review, we address: 1) the effects of aging on autonomic nervous system control of

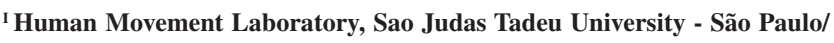
SP, Brazil.

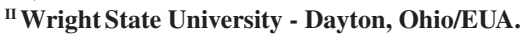

III Hypertension Unit, Heart Institute (INCOR), Faculdade de Medicina, Universidade de São Paulo - São Paulo/SP, Brazil.

Tel.: 55112799.1909

Email:prof.rogeriowichi@usjt.br

Received for publication on August 29, 2008

Accepted for publication on November 05, 2008 the cardiovascular system; 2) the effect of aging on physical fitness; 3) the benefits of chronic exercise to prevent cardiovascular changes in the context of aging. A Pubmed search used the following key words: aging, cardiovascular system, autonomic nervous system, physical exercise and training exercise.

\section{AUTONOMIC NERVOUS SYSTEM CONTROL OF THE CARDIOVASCULAR SYSTEM AND AGING}

In 1920, Walter Canon said that the autonomic nervous system was essential to maintain the balance of the organism; he defined this process as "homeostasis." ${ }^{4} \mathrm{We}$ know that that the autonomic nervous system is an important neuromodulator of the cardiovascular and metabolic systems in humans. The autonomic nervous system allows the central nervous system to maintain homeostasis in the context of both acute and chronic changes in physiological and pathological states. Cardiovascular diseases are associated with autonomic changes that include a decrease in parasympathetic and/or an increase in sympathetic modulation.

Aging is known to alter the neurohormonal mechanisms that control the cardiovascular system. Published reports have 
demonstrated a decline in sinoatrial node parasympathetic activity $^{5,6}$ and an increase in sympathetic activity in the heart and vascular system with aging. ${ }^{5}$

The impairment of cardiac-vagal neurons appears to be the major determinant of changes in the control of heart rate that come with aging, since aging reduces the tachycardia that may be induced by atropine in humans and animals. ${ }^{7}$ The study performed by our group demonstrated that the vagal effect as evaluated by methylatropine injection was greater in young rats than in old rats; young rats showed a lower intrinsic heart rate after methylatropine and propranolol blockade (Figure 1). ${ }^{8}$

A

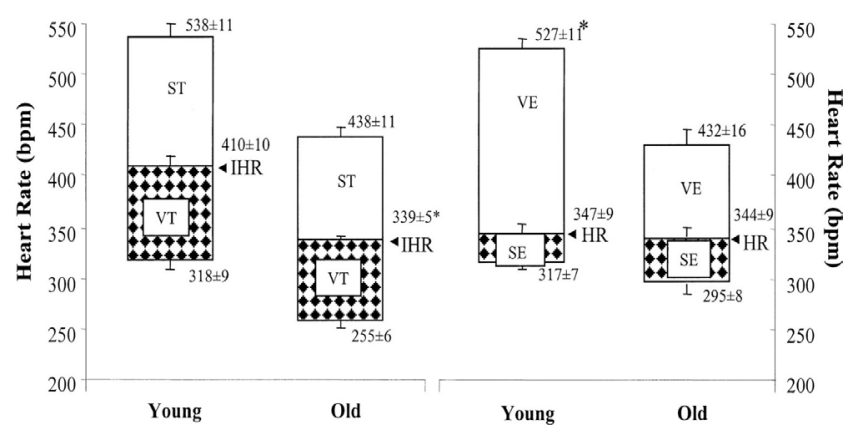

Figure 1 - $A$ : Graphs showing no differences in sympathetic (ST) and vagal (VT) tone between young and old rats. The intrinsic HR (IHR) was lower in old rats. $B$ : The increase in HR (from $347 \pm 9$ to $527 \pm 11$ beats/ min) after methylatropine injection [vagal effect (VE)] was higher in young rates than in older specimens. * Significant difference between young and old rats $(P<0.05)$.

Reduced vagal function and intrinsic heart rate were also observed in older individuals. ${ }^{9}$ Stratton et al. studied the cardiovascular effects of parasympathetic blockade and demonstrated small increases in heart rate, cardiac index, systolic blood pressure, and early diastolic filling rate in older as compared to younger people. ${ }^{10}$ Depression of respiratory sinus arrhythmia with age also suggests a decrease in parasympathetic influence on sinus node function. ${ }^{11}$ Dysfunction in the activity of the neural portion (afferent, central or efferent) of the vagal system and the cardiac muscarinic receptor may be involved in the parasympathetic changes associated with aging.

Increased sympathetic activity has been indicated by the rate of noradrenaline secretion and recordings of sympathetic nerve activity associated with the skeletal muscle and heart. Studies have shown that basal noradrenaline plasma concentrations are elevated in elderly populations. ${ }^{12,13}$ Increased muscle sympathetic nerve activity is present in elderly normotensive men and women. Sympathetic nerve activity is almost two times higher in 65-year-olds than in 25-year-olds. ${ }^{14,15}$ Cardiac sympathetic activity is also elevated in the first group. This is probably due to a reduced neuronal uptake of noradrenaline and an increased sympathetic nerve discharge rate. ${ }^{13}$ The age-related increases in sympathetic nervous system activity under resting conditions seem to be related mainly to a primary increase in central sympathetic nerve discharge. ${ }^{16}$

Aging per se induces changes in the baroreflex control of heart rate. The decline of baroreflex sensitivity was documented in experimental older animals and humans. Baroreceptor stimulation by phenylephrine or sodium nitroprusside induced a lower decrease in the heart reflex in older as compared to younger individuals. ${ }^{7}$ Experiments conducted by our group demonstrated that older rats exhibited impaired sensitivity of the baroreflex control of heart rate. ${ }^{8,17}$ The baroreflex bradycardia induced by increasing the arterial pressure after phenylephrine injection was significantly lower in old rats as compared to young rats. The cardiac response to nitroprusside sodium injection was also depressed in older as compared with younger rats (Figure 2). The age-related impairment of baroreflex sensitivity has been associated with alterations in arterial compliance, changes in central autonomic integration, reduction of vagal outflow and decreased muscarinic sinoatrial node receptor density. ${ }^{18-20}$

Heart rate and arterial pressure homeostasis may be compromised with age. Resting heart rates remain unchanged or even decrease slightly with age. ${ }^{21,8,22}$ Cardiac output is also preserved since the ejection fraction and stroke volume remain constant. $^{22}$

The decrease in autonomic modulation associated with advancing age is also reflected in changes in heart rate

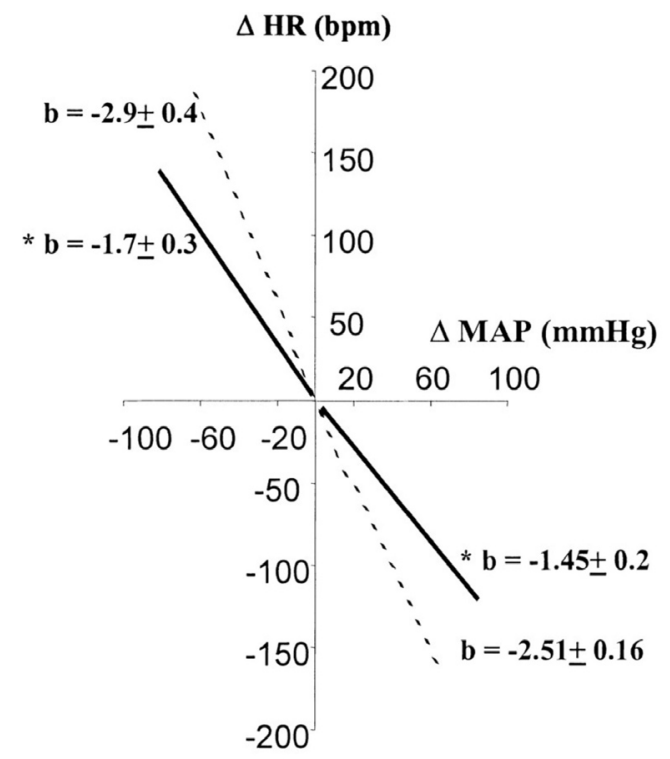

Figure 2 - Baroreflex control of heart rate $(\Delta \mathrm{HR})$ in young (dashed line) and old (solid line) rats. The HR slopes during increases and decreases in mean arterial pressure ( $\triangle \mathrm{MAP}$ ) were significantly reduced in old rats as compared with younger specimens. * Significant differences between young and old rats $(P<0.05)$. 


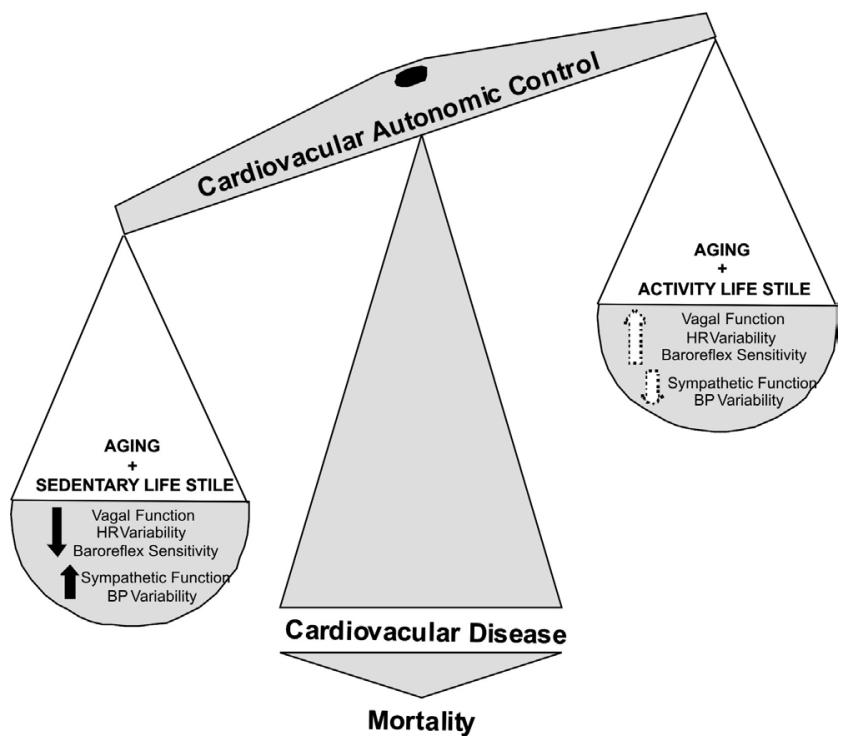

Figure 3 - A schematic representation of age-related alterations to the autonomic nervous system, and of the role of chronic exercise in reducing or preventing these alterations. Aging combined with a sedentary lifestyle is associated with changes in the autonomic nervous system's control of the cardiovascular system. Autonomic changes involve decreases in vagal function, HR variability and baroreflex sensitivity, as well as increased sympathetic function and BP variability. These changes are associated with high rates of cardiovascular disease and mortality. Chronic exercise prevents these autonomic changes and reduces the rates of cardiovascular disease and mortality as they relate to aging.

(HRV), blood pressure variability (BPV) and their frequency components. Changes in HR and BP variability are thought to be detrimental to cardiovascular health. For example, the Framingham study demonstrated that reduced HRV was a predictor of new cardiac events and hypertension in a middleaged population. ${ }^{23}$ Therefore, HR variability has been used as an important predictor of death and non-fatal cardiovascular dysfunction..$^{24}$ The aging process is associated with a reduction in HR variability, linked to an age-related decline in parasympathetic regulation and greater sympathetic modulation. ${ }^{25-27}$ Autonomic modulation, estimated through the use of HR variability frequency components, changes with age. Clinical and experimental studies have shown that the spectral power of the high frequency (HF) component of HRV reflects parasympathetic modulation, and the low frequency (LF) range of HRV reflects vagal, mostly sympathetic, modulations. ${ }^{28}$ In addition, the LF component of BP variability is a reflection of sympathetic modulation of the circulation. ${ }^{28}$ Healthy older subjects exhibited lower HF components and higher LF components at rest when compared to younger subjects, and consequently, a higher sympathovagal balance (LF/HF). ${ }^{27}$ The $\mathrm{LF} / \mathrm{HF}$ ratio is considered by some investigators to reflect sympathovagal balance or sympathetic modulations. ${ }^{28,31,32}$ This suggests that there may be some increase in the sympathetic influence on HR variability with increasing age.
Age is associated with increased BP and BP variability as well as a decrease in arterial compliance and arterial system distensibility. The decrease in arterial compliance is a powerful determinant of cardiovascular risk. ${ }^{34}$ Furthermore, the hyperactivity of the sympathetic nervous system contributes to increased arterial pressure. Studies have investigated the effect of age on resting BP variability and have suggested an increase in baseline BPV with aging. ${ }^{35,36}$ $\mathrm{BP}$ variability is associated with the $\mathrm{LF} / \mathrm{HF}$ ratio, and this in turn may reflect changes in the sympathovagal balance. ${ }^{35}$

\section{PHYSICAL FITNESS, AUTONOMIC NERVOUS SYSTEM AND AGING}

The changes in the autonomic nervous system, glycemic control, and morphological and structural aspects of the cardiovascular system, are all likely related to low physical fitness associated with the aging process. Although the literature does not suggest any real consensus, there is evidence that suggests that low physical fitness may lead to autonomic changes..$^{37,38}$ The impairment in physical fitness leads to functional disability and a loss of independence, consistent with increasing utilization of healthcare resources.

Maximal consumption of oxygen (VO2max) is correlated with performance during endurance-based exercise. There exists long-standing evidence that $\mathrm{VO} 2 \mathrm{max}$ and performance decline progressively with age. ${ }^{39} \mathrm{~A}$ decrease in VO2max is associated with increased risk of cardiovascular disease and mortality. ${ }^{40,41}$ Studies have identified an inverse relationship between $\mathrm{VO} 2 \max$ and age in trained and untrained populations. ${ }^{42,43}$ However, the decline in VO2max is smaller in endurance-trained male athletes than in sedentary men. ${ }^{44-46}$ Since VO2max is the product of maximal heart rate, maximal stroke volume, and maximal arteriovenous $\mathrm{O} 2$ difference, any change in heart rate or myocardial contractility will alter VO2max. This is noticeable in the aged, for whom cardiovascular responses to exercise are blunted. This manifests as a reduction in exercise-induced tachycardia and myocardial contractility. ${ }^{36}$ The reduced degree of tachycardia during exercise in the elderly may be related to reduced cardiac function. Cross-sectional investigations suggest that good cardiorespiratory fitness is associated with enhanced vagal activity. ${ }^{37,38}$ Subjects with superior exercise capacity have significantly higher vagal HR modulation during exercise than do those with poor physical fitness. ${ }^{47}$ The intensity of the exercise level at which vagal modulation disappears is also significantly higher in trained individuals. This supports the hypothesis that cardiac vagal function is related to aerobic fitness in middle-aged and elderly subjects. ${ }^{47}$ 


\section{CHRONIC PHYSICAL EXERCISE, AUTONOMIC NERVOUS SYSTEM PERFORMANCE AND AGING}

Cardiovascular, metabolic and autonomic improvements induced by chronic exercise have led many investigators to suggest that regular exercise is an important intervention that can help prevent physiological changes associated with aging. Individuals that are physically active show attenuation of the physiological alterations related to aging, with a commensurate reduction in cardiovascular risk. We have shown that regular exercise in younger ${ }^{14,48}$ and older normotensive rats ${ }^{49}$ improved the autonomic control of cardiovascular function. Regular exercise in animals and humans results in adaptation of the autonomic nervous system, which is most commonly observed as reduced HR at rest. In humans, resting bradycardia is associated with a decrease in intrinsic HR as well as an altered autonomic balance, leading to parasympathetic dominance. ${ }^{50-52}$ This is thought to be mediated in part by an increase in cardiac vagal tone. ${ }^{53}$ The mechanisms by which exercise produces changes in autonomic control are unknown; however, there is evidence of alterations in the central afferent and efferent pathways and in the effector organs (receptor function). ${ }^{54,55}$ Danson and Paterson ${ }^{56}$ showed that nitric oxide-mediated vagal-induced bradycardia is enhanced after exercise training. Transgenic studies involving the transfer of nitric oxide synthase into the atrial wall mimicked the exercise effects of the vagal phenotype, suggesting that nitric oxide synthase may be an important protein to increase cardiac vagal function..$^{7}$

Studies have provided inconclusive results regarding the effects of aerobic training on HR variability in elderly subjects. Stein et al..$^{58}$ observed that 12 -month aerobic training in healthy older adults promoted an increase in HR variability. These researchers also showed that the increased HRV was maintained for more than one year with regular training. Another study demonstrated that HR variability increased in older men after a 6-month period of high-intensity training at 50-85\% HR reserve for 180-225 $\mathrm{min} / \mathrm{wk} .^{58}$ On the other hand, Uusitalo et al..$^{59}$ observed no changes in HR variability in older men after 5 years of lowintensity training at 40-60\% VO2max for 30-60 min/day, 3-5 days/wk. The different results from these studies may be due to the different exercise loads. The HRV changes are directly related to the intensity, duration and frequency of aerobic training.

Decreased baroreflex sensitivity is attenuated in endurance-trained adults as compared to sedentary ones. ${ }^{60}$ Evidence from cross-sectional studies shows that baroreflex sensitivity is greater in middle-aged and older adults who exercise regularly as compared to those who lead a sedentary lifestyle. ${ }^{61,62}$ Recently, Okazaki et al ${ }^{63}$ suggested that the adaptation of baroreflex sensitivity may be more pronounced after moderate training, since intense exercise was not found to result in greater changes. The mechanisms that modify baroreflex sensitivity in the elderly with regular aerobic exercise have not been determined. Baroreflex sensitivity changes promoted by physical exercise have been associated with alterations in the afferent, central and efferent components of the baroreflex pathway. For example, Tanaka et al ${ }^{64}$ showed that physical activity improved the compliance of large elastic arteries that contain arterial baroreceptors (namely the ascending aorta and carotid sinus). Increased shear stress during exercise may also enhance the release of endothelial factors and may contribute to improved arterial compliance. The enhanced arterial compliance associated with regular exercise could enhance stimulus transduction and afferent responsiveness. Also, the higher vagal tone in the heart after regular exercise suggests an improvement of the vagal reserve in the context of baroreceptor-mediated HR response. ${ }^{53}$ Regular exercise may increase baroreflex sensitivity in older humans by augmenting the muscarinic receptor density ${ }^{60}$ and increasing arterial baroreceptor sensitivity.

\section{CLINICAL IMPLICATIONS AND PERSPECTIVES}

We conclude that physical exercise is an important tool to prevent and reduce cardiovascular autonomic changes associated with age. Studies have shown that regular exercise improves baroreflex sensitivity and heart rate variability, increases parasympathetic outflow, and decreases sympathetic outflow, thereby reducing cardiopathies related to age. The mechanisms by which chronic exercise reduces and prevents the autonomic changes related to age have been associated with alterations in the effector organs (receptor function) and with changes in the afferent, central and efferent components of the autonomic nervous system pathway.

The effects of exercise on cardiovascular morbidity and mortality have yet to be elucidated, in particular with respect to the intensity and duration of regular exercise that is required to achieve a clinically meaningful reduction in cardiovascular risk. The optimal "dose" of exercise required to achieve maximal improvement in these variables is not yet clear. More studies should be conducted to investigate this question. 


\section{REFERENCES}

1. Sachdev M, Sun JL, Tsiatis AA, Nelson CL, Mark DB, Jollis JG. The prognostic importance of comorbidity for mortality in patients with stable coronary artery disease. J Am Coll Cardiol. 2004;43:576-82.

2. Backer G, Ambrosioni E, Borch-Jonhsen K. European guidelines on cardiovascular disease prevention in clinical practise. Third Joint Task Force of European and other Societies on Cardiovascular Disease Prevention in Clinical Practise. Eur J Cardiovascular Prev Rehab. 2003;10(Suppl 1):S1-S78.

3. Bell C, Seals DR, Monroe MB, Day DS, Shapiro LF, Johnson DG, et al. Tonic sympathetic support of metabolic rate is attenuated with age, sedentary lifestyle, and female sex in healthy adults. J Clin Endocrinol Metab. 2001;86(9):4440-4.

4. Cannon WB. The Wisdom of the Body. New York: In WW Norton, publisher, 1939.

5. Mark AL. Sympathetic dysregulation in heart failure: mechanisms and therapy. Clin Cardiol 1995;18:I3-8.

6. Eckberg DL, Drabinsky M, Braunwald E. Defective cardiac parasympathetic control in patients with heart disease. N Engl J Med. $1971 ; 285: 877-83$.

7. Ferrari AU, Daffonchio A, Albergati F, Mancia G. Differential effects of aging on the heart rate and blood pressure influences of arterial baroreceptors in awake rats. J Hypertens. 1991;9:615-21.

8. Irigoyen MC, Moreira ED, Werner A, Ida F, Pires MD, Cestari IA, et al. Aging and baroreflex control of RSNA and heart rate in rats. Am J Physiol Regul Integr Comp Physiol. 2000;279:R1865-71.

9. Fleg JL, Kennedy HL. Cardiac arrhythmias in a healthy elderly population: detection by 24-hour ambulatory electrocardiography. Chest. 1982;81:302-7.

10. Stratton JR, Levy WC, Caldwell JH, Jacobson A, May J, Matsuoka D, et al. Effects of aging on cardiovascular responses to parasympathetic withdrawal. J Am Coll Cardiol. 2003;41:2077-83.

11. Kuo TB, Lin T, Yang CC, Li CL, Chen CF, Chou P. Effect of aging on gender differences in neural control of heart rate. Am J Physiol. 1999; 277: H2233-9.

12. Rubin PC, Scott PJ, McLean K, Reid JL. Noradrenaline release and clearance in relation to age and blood pressure in man. Eur J Clin Invest 1982;12:121-5.

13. Esler MD, Turner AG, Kaye DM, Thompson JM, Kingwell BA, Morris $\mathrm{M}$, et al. Aging effects on human sympathetic neuronal function. Am J Physiol. 1995;268:R278-85.

14. Negrao CE, Moreira ED, Santos MC, Farah VM, Krieger EM. Vagal function impairment after exercise training. J Appl Physiol. 1992;72:1749-53.

15. Dinenno FA, Jones PP, Seals DR, Tanaka H. Limb blood flow and vascular conductance are reduced with age in healthy humans: relation to elevations in sympathetic nerve activity and declines in oxygen demand. Circulation. 1999;100:164-70.

16. Esler M, Hastings J, Lambert G, Kaye D, Jennings G, Seals DR. The influence of aging on the human sympathetic nervous system and brain norepinephrine turnover. Am J Physiol Regul Integr Comp Physiol. 2002;282:R909-16.
17. Werner A, Rosa NR, Oliveira AR, Fernandes TG, Bello AA, Irigoyen MC. Changes in blood pressure control in aged rats. Braz J Med Biol Res. 1995;28:603-7.

18. Itoh H, Bunag RD. Aging reduces cardiovascular and sympathetic responses to NTS injections of serotonin in rats. Exp Gerontol. 1992;27:309-20.

19. Dauchot P, Gravenstein JS. Effects of atropine on the electrocardiogram in different age groups. Clin Pharmacol Ther. 1971;12:274-80.

20. Brodde OE, Konschak U, Becker K, Ruter F, Poller U, Jakubetz J, et al. Cardiac muscarinic receptors decrease with age. In vitro and in vivo studies. J Clin Invest. 1998;101:471-8.

21. McCarty R. Sympathetic-adrenal medullary and cardiovascular responses to acute cold stress in adult and aged rats. J Auton Nerv Syst. $1985 ; 12: 15-22$

22. Rodeheffer RJ, Gerstenblith G, Becker LC. Exercise cardiac output is maintained with advancing age in healthy human subjects: cardiac dilatation and increased stroke volume compensate for a diminished heart rate. Circulation. 1984;69:203-13.

23. Tsuji H, Larson MG, Venditti FJ Jr, Manders ES, Evans JC, Feldman $\mathrm{CL}$, et al. Impact of reduced heart rate variability on risk for cardiac events. The Framingham Heart Study. Circulation. 1996;94:2850-5.

24. Kleiger RE, Miller JP, Bigger JT, Jr., Moss AJ. Decreased heart rate variability and its association with increased mortality after acute myocardial infarction. Am J Cardiol. 1987;59:256-62.

25. Colosimo A, Giuliani A, Mancini AM, Piccirillo G, Marigliano V. Estimating a cardiac age by means of heart rate variability. Am J Physiol. 1997;273:H1841-7.

26. Piccirillo G, Bucca C, Bauco C, Cinti AM, Michele D, Fimognari FL, et al. Power spectral analysis of heart rate in subjects over a hundred years old. Int J Cardiol. 1998;63:53-61.

27. Pfeifer MA, Weinberg CR, Cook D, Best JD, Reenan A, Halter JB. Differential changes of autonomic nervous system function with age in man. Am J Med. 1983;75:249-58.

28. Malliani A, Pagani M, Lombardi F, Cerutti S. Cardiovascular neural regulation explored in the frequency domain. Circulation. 1991;84:48292.

29. Stauss HM, Mrowka R, Nafz B, Patzak A, Unger T, Persson PB. Does low frequency power of arterial blood pressure reflect sympathetic tone? J Auton Nerv Syst. 1995;54:145-54.

30. Catai AM, Chacon-Mikahil MP, Martinelli FS, FortiVA, Silva E, Golfetti $\mathrm{R}$, et al. Effects of aerobic exercise training on heart rate variability during wakefulness and sleep and cardiorespiratory responses of young and middle-aged healthy men. Braz J Med Biol Res. 2002;35:741-52.

31. Appel ML, Berger RD, Saul JP, Smith JM, Cohen RJ. Beat to beat variability in cardiovascular variables: noise or music? J Am Coll Cardiol. 1989;14:1139-48.

32. Montano N, Ruscone TG, Porta A, Lombardi F, Pagani M, Malliani A. Power spectrum analysis of heart rate variability to assess the changes in sympathovagal balance during graded orthostatic tilt. Circulation. 1994;90:1826-31 
33. Cleroux J, Giannattasio C, Bolla G , CuspidiC, Grassi G, Mazzola C, et al. Decreased cardiopulmonary reflexes with aging in normotensive humans. Am J Physiol. 1989;257:H961-8.

34. Blacher J, London GM, Safar ME, Mourad JJ. Influence of age and end-stage renal disease on the stiffness of carotid wall material in hypertension. J Hypertens. 1999;17:237-44.

35. Veerman DP, Imholz BP, Wieling W, Karemaker JM, van Montfrans GA. Effects of aging on blood pressure variability in resting conditions. Hypertension. 1994;24:120-130.

36. Parati G, Frattola A, Di Rienzo M, Castiglioni P, Mancia G. Broadband spectral analysis of blood pressure and heart rate variability in very elderly subjects. Hypertension. 1997;30:803-8.

37. Maciel BC, Gallo JL, Marin Neto JA, Lima Filho EC, Terra FJ, Manco JC. Parasympathetic contribution to bradycardia induced by endurance training in man. Cardiovasc Res. 1985;19:642-8.

38. Shin K, Minamitani H, Onishi S, Yamazaki H, Lee M. Autonomic differences between athletes and nonathletes: spectral analysis approach. Med Sci Sports Exerc. 1997;29:1482-90

39. Saltin B, Astrand PO. Maximal oxygen uptake in athletes. J Appl Physiol. $1967 ; 23: 353-8$

40. Blair SN, Kohl HW, Barlow CE, Paffenbarger RS Jr, Gibbons LW, Macera CA. Changes in physical fitness and all-cause mortality. A prospective study of healthy and unhealthy men. JAMA. 1995;273:1093-

41. Binder EF, Birge SJ, Spina R, Spina R, Ehsani AA, Brown M, et al. Peak aerobic power is an important component of physical performance in older women. J Gerontol A Biol Sci Med Sci. 1999;54:M353-6.

42. Tanaka H, Desouza CA, Jones PP, Stevenson ET, Davy KP, Seals DR. Greater rate of decline in maximal aerobic capacity with age in physically active vs. sedentary healthy women. J Appl Physiol. 1997;83:1947-53

43. Wilson TM, Tanaka H. Meta-analysis of the age-associated decline in maximal aerobic capacity in men: relation to training status. Am J Physiol Heart Circ Physiol. 2000;278:H829-34.

44. Heath GW, Hagberg JM, Ehsani AA, Holloszy JO. A physiological comparison of young and older endurance athletes. J Appl Physiol. 1981;51:634-40.

45. Hagberg JM. Effect of training on the decline of VO2max with aging. Fed Proc. 1987;46:1830-3.

46. Rowell LB. Human Circulation: Regulation During Physical Stress. In New York: Oxford Univ. Press. 1986

47. Tulppo MP, Makikallio TH, Seppanen T, Laukkanen RT, Huikuri HV. Vagal modulation of heart rate during exercise: effects of age and physical fitness. Am J Physiol. 1998;274:H424-9.

48. Gava NS, Veras-Silva AS, Negrao CE, Krieger EM. Low-intensity exercise training attenuates cardiac beta-adrenergic tone during exercise in spontaneously hypertensive rats. Hypertension. 1995;26:1129-33.

49. De Angelis KL, Oliveira AR, Werner A, Bock P, Bello-Klein A, Fernandes TG, et al. Exercise training in aging: hemodynamic, metabolic, and oxidative stress evaluations. Hypertension. 1997;30:76771.
50. Katona PG, McLean M, Dighton DH, Guz A. Sympathetic and parasympathetic cardiac control in athletes and nonathletes at rest. J Appl Physiol. 1982;52:1652-7.

51. Smith ML, Hudson DL, Graitzer HM, Raven PB. Exercise training bradycardia: the role of autonomic balance. Med Sci Sports Exerc. 1989;21:40-4.

52. Sugawara J, Murakami H, Maeda S, Kuno S, Matsuda M. Change in post-exercise vagal reactivation with exercise training and detraining in young men. Eur J Appl Physiol. 2001;85:259-63.

53. De Angelis K, Wichi RB, Jesus WR, Moreira ED, Morris M, Krieger EM, et al. Exercise training changes autonomic cardiovascular balance in mice. J Appl Physiol. 2004;96:2174-8.

54. Brum PC, Da Silva GJ, Moreira ED, Ida F, Negrao CE, Krieger EM. Exercise training increases baroreceptor gain sensitivity in normal and hypertensive rats. Hypertension. 2000;36:1018-22.

55. Favret F, Henderson KK, Clancy RL, Richalet JP, Gonzalez NC. Exercise training alters the effect of chronic hypoxia on myocardial adrenergic and muscarinic receptor number. J Appl Physiol. 2001;91:1283-8.

56. Danson EJ, Paterson DJ. Enhanced neuronal nitric oxide synthase expression is central to cardiac vagal phenotype in exercise-trained mice. J Physiol. 2003;546:225-32

57. Mohan RM, Heaton DA, Danson EJ, Danson EJ, Krishnan SP, Cai S, et al. Neuronal nitric oxide synthase gene transfer promotes cardiac vagal gain of function. Circ Res. 2002;91:1089-91.

58. Stein PK, Ehsani AA, Domitrovich PP, Kleiger RE, Rottman JN. Effect of exercise training on heart rate variability in healthy older adults. Am Heart J. 1999;138:567-76.

59. Uusitalo AL, Laitinen T, Vaisanen SB, Lansimies E, Rauramaa R. Physical training and heart rate and blood pressure variability: a 5-yr randomized trial. Am J Physiol Heart Circ Physiol. 2004;286:H18216.

60. Monahan KD, Dinenno FA, Tanaka H, Clevenger CM, Desouza CA, Seals DR. Regular aerobic exercise modulates age-associated declines in cardiovagal baroreflex sensitivity in healthy men. J Physiol. 2000;529:263-71

61. Carter JB, Banister EW, Blaber AP. Effect of endurance exercise on autonomic control of heart rate. Sports Med. 2003;33:33-46.

62. Davy KP, Desouza CA, Jones PP, Seals DR. Elevated heart rate variability in physically active young and older adult women. Clin Sci (Lond). 1998;94:579-84.

63. Okazaki K, Iwasaki K, Prasad A, Palmer MD, Martini ER, Fu Q, et al. Dose-response relationship of endurance training for autonomic circulatory control in healthy seniors. J Appl Physiol. 2005;99:1041-

64. Tanaka H, Dinenno FA, Monahan KD, Clevenger CM, Desouza CA, Seals DR. Aging, habitual exercise, and dynamic arterial compliance. Circulation. 2000;102:1270-5 